\title{
Sur y norte de la cultura del nuevo mundo ${ }^{1}$
}

\author{
Claudio Véliz
}

\begin{abstract}
¿A qué se debe el enorme contraste en nuestro continente entre los logros económicos del norte y el estancamiento del sur? Este ensayo sugiere que las contrucciones culturales más importantes de las respectivas metrópolis coloniales -la Contrarreforma Católica española y la Revolución Industrial inglesa- generaron estilos diferentes que se perpetuaron en las nuevas sociedades transplantadas. Así, si en el mundo iberoamericano siempre se han valorado la estabilidad, la permanencia y la continuidad, en la América anglosajona se han legitimado el cambio, la novedad y el riesgo. Contrapuntos como estos se reflejan en las instituciones, las leyes, los regímenes políticos, la religiosidad, el lenguaje, las costumbres y han determinado la modernidad industrial y el poderío económico de la región del norte a diferencia de lo que ha sucedido en el sur.
\end{abstract}

Cualquier cosa se puede comparar con cualquiera otra, con resultados que dependen tanto de la intención con que se hace la comparación como de los méritos de la misma. Existen, sin embargo, ciertas comparaciones que el devenir de la historia, o de la vida cotidiana, nos imponen con fuerza irresistible. Así es como las inevitables comparaciones con nuestros hermanos, con nuestros adversarios en el deporte, con nuestros rivales en asuntos sentimentales o con nuestros vecinos, nos ayudan

\footnotetext{
${ }^{1}$ Exposición realizada en el "Simposio sobre Cultura, Valores y su Influencia sobre la Competitivided y el Desarrollo Sostenible en Latinoamérica", patrocinado por el Instituto Centroamericano de Administración de Empresas (INCAE), realizado en Costa Rica, entre los días 28 y 30 de junio de 1996.
} 
decididamente a comprender nuestra circunstancia social inmediata. Pero quienes vivimos en el nuevo mundo de Américo Vespucci nos vemos desafiados además por la comparación porfiada y primordial que nos imponen cinco siglos de historia, entre el sur y el norte de nuestro mundo, entre las dos más grandes sociedades transplantadas de nuestros tiempos, vástagos respectivamente de los dos imperios dominantes de la historia moderna, nacidos precisamente cuando éstos cruzaban el umbral de su grandeza; el uno de habla castellana y portuguesa, el otro de habla inglesa; el uno protagonizando hace ya más de un siglo sucesivas etapas de prosperidad y poderío sin precedentes en la historia mundial, y el otro, con contadísimas excepciones regionales, frecuentemente empantanado en circunstancias económicas que distan mucho de ser felices o particularmente auspiciosas.

Una observación preliminar y necesaria acerca de la compleja circunstancia cultural de las dos mitades de nuestro hemisferio es que no obstante los indudables méritos y logros de las riquísimas culturas precolombinas, nunca llevaron éstos a una "americanización" de las culturas intrusas. No se trata aquí de argüir que esto merezca lamentación o aplauso, sino sencillamente anotar un hecho tan indiscutible como importante. Por el contrario, de tal modo han retenido los transplantes ibéricos y anglosajones sus características definitivas y preponderantes que, como experiencia histórica contemporánea, no dejan espacio para dudas acerca de sus respectivos origenes. La cultura dominante de la sociedad del ámbito sur del continente no puede sino tener a España y Portugal como naciones progenitoras, mientras que todos sabemos que los blancos acantilados de Dover son fácilmente visibles tanto desde Cincinatti y Milwaukee como desde Tucson y Pasadena. Es clarísimo que Unuguay, Colombia y Costa Rica han cambiado mucho durante los últimos cuatro siglos y que estos cambios, con escasas excepciones, han tendido a atenuar la impronta ibérica; sin embargo, es también obvio que no existe en el mundo una tradición cultural más próxima a Uruguay, Colombia y Costa Rica que la de España. Más aún, las importantes y bienvenidas corrientes migratorias que tanto han enriquecido y matizado las tradiciones culturales de nuestros paises, o no han querido o no han podido resistir el abrazo cultural predominantemente ibérico de la sociedad anfitriona. Bastan una o dos generaciones para que la retención de la lengua y costumbres de las familias inmigrantes o el origen preciso de apellidos como Wasmosy, Frei, Kubitschek, Frondizi, Menem, Stroessner, Bucaram o Fujimori no pasen más allá de ser curiosidades anecdóticas. 
Los Estados Unidos y Canadá han tenido experiencias parecidas, aún cuando durante las últimas décadas ha habido intentos, que no han sido extraordinariamente exitosos, por impedir o retardar los inevitables procesos de asimilación cultural. La tendencia secular, sin embargo, ha sido más o menos la misma que en el hemisferio sur. Esto es, tanto los Estados Unidos como Canadá han experimentado modificaciones muy grandes desde la época de sus respectivos origenes coloniales, pero no tan grandes como para borrar los rasgos definitivos de un estilo y disposición culturales que invariablemente, y sin mayor esfuerzo, confirman su maciza ascendencia británica.

La persistencia de las culturas transplantadas se nota asimismo en el modo en que éstas afectan a grupos de inmigrantes de culturas europeas vigorosas que se han establecido en el norte y el sur del continente. Después de varias generaciones, la importante emigración italiana tanto a los Estados Unidos como Argentina, por ejemplo, ha generado grupos naturalmente conscientes y orgullosos de sus orígenes europeos, pero con diferencias radicales -basta mencionar Buenos Aires y Chicago-que reflejan fielmente sus nuevas circunstancias culturales ibéricas y anglosajonas.

No son pocos quienes argumentarian que.tanto en el norte como en el sur del nuevo mundo, los sanguinarios y exitosos procesos independentistas marcaron un quiebre claro y permanente de lo que hasta entonces podría haberse interpretado, erróneamente, como una continuidad cultural ininterrumpida. Pero esto ignora que la independencia de las colonias no significó, leyendas negras no obstante, el rechazo de las culturas progenitoras; los granjeros republicanos de New Hampshire y Rhode Island no dejaron de usar la lengua inglesa, ni dieron las espaldas al Common Law para dirimir sus entuertos, ni abrazaron creencias religiosas distantes de las de sus padres, ni adoptaron un modo de producir y consumir irreconocible por sus abuelos. Asimismo, en el sur del continente, donde el sentimiento antiespañol fue particularmente amargo y obstinado, el nuevo liderazgo republicano -como lo observara Andrés Bello- continuó utilizando la lengua castellana para atacar la tradición cultural española, no cambió de religión, ni adoptó sistemas legales distantes de los heredados de la metrópolis ibérica, y. aparte algunos patéticos intentos por imitar a los Estados Unidos mediante la adopción de sus normas constitucionales, los nuevos regímenes independientes retuvieron e incluso exacerbaron el robusto centralismo que la España carolina había heredado de Habsburgos y Borbones. Lo que sí es posible proponer con algún énfasis, es que las repúblicas iberoameri- 
canas se las ingeniaron para independizarse decididamente del proceso de la decadencia española, que hasta entonces les había afectado sólo muy marginalmente. El movimiento de independencia entregó a los nuevos americanos la contundente victoria negada a los peninsulares que sin duda alguna reforzó la afirmación cultural de los unos y la obstinada decadencia de los otros.

Esta continuidad robusta y persistente con las culturas metropolitanas otorga a las sociedades americanas la calidad de copartícipes, si no coautoras, de las realizaciones señeras de sus progenitores europeos, pero ha sido injustamente ignorada por una historiografia apologética que insiste en asignarle a nuestro continente una calidad subordinada, secundaria y dependiente negando, por consiguiente, la importante contribución que nuestras sociedades transplantadas han hecho a dos de los grandes logros culturales de la historia moderna.

Es tan dificil como injusto excluir,.por ejemplo, la participación americana de la gestación y destino eventual tanto de la Revolución Industrial como de la Contrarreforma Católica, que sin duda alguna han sido las creaciones cumbres de las dos culturas imperiales preeminentes de la historia moderna. En la ausencia del mundo americano, la Contrạrreforma española es prácticamente inconcebible, puesto que la respuesta al desafio luterano tendría que imaginarse realizada sin beneficio del clima intelectual y moral generado por el debate acerca de las responsabilidades de la corona y sus súbditos frente a un mundo inocente, si no del pecado original, indudablemente del europeo; un debate, vale la pena agregar, que reclamó y alentó unạ disposición tan severa en cuanto a verdades doctrinarias como activista en el mundo de los vivos, tendencia que luego habría de fructificar en Trento. Habria también que imaginar una Compañía de Jesús creciendo y madurando entre cuatro murallas palaciegas, muy distantes del brutal desafio de las fronteras espirituales y políticas de la frontera amazónica y del "Flandes Indiano" de los araucanos; un siglo de oro sin el abundante capital de arrogancia y afirmación acumulado durante cien años de victorias; y arriesgando una banalidad insufrible, habría que imaginar la gran cruzada españanola, sin beneficio del torrente indiano de metales preciosos.

Tan importante como en su gestación fue el papel de las Indias en el proceso ulterior y el apogeo de la Contrarreforma, puesto que además de ser nuestro continente, durante un cuarto de milenio, el ámbito exclusivamente tridentino más extenso del mundo, fue también aquél en que las directivas que emanaron del gran Concilio fueron aceptadas de modo más leal, duradero y fecundo, reafirmando así la vigorosa continuidad 
del parentesco cultural entre la patria ibérica y la criatura americana. Aquellas Indias, inocentes de lecturas peligrosas y limpias de contagios 'heréticos, respondieron con una verdadera orgía de creatividad, forma y colorido al mandato tridentino que exigió el reclutamiento de la escultura, la arquitectura y la pintura en la milicia jesuita que marchó a la defensa de la fe amenazada, y no es aventurado afirmar que desde entonces nada hemos realizado en este orden de cosas que supere la espléndida proeza del barroco indiano.

Igualmente dificil tarea sería imaginar el origen y curso eventual de la Revolución Industrial inglesa, si se les considera separados absolutamente de la génesis y crecimiento de los Estados Unidos. Tanto los disidentes de la Nueva Inglaterra como aquéllos que, lejos de Westminster, protagonizaron el desarrollo temprano de la metalurgia industrial y la banca inglesas, abrazaban creencias religiosas similares y habian adoptado una misma modalidad de conducta que aunaba un duro régimen de trabajo con un estilo de vida excepcionalmente austero. Asimismo, las familias inglesas que decidieron emigrar fueron precisamente las que con más celo preferian esta manera de vivir y acercarse a su salvación espiritual, y lo hicieron convencidas que en América del norte podrían construir la nueva Jerusalén,..distante de los vicios y tentaciones de la Babilonia europea que les había visto nacer. En ambos casos, la acumulación de capital industrial no fue la resultante de un disciplinado empeño por hacer fortuna, sino una consecuencia marginal de un modo de vida que tanto Max Weber como R.H. Tawney justamente han asociado con el primer florecimiento del industrialismo moderno.

Así como no existe la menor duda acerca del lugar y momento histórico en que se inició la Revolución Industrial, tampoco puede haberla acerca del domicilio actual del industrialismo moderno. Hubo quienes no hace mucho estimaban que con el ocaso del imperio británico, sería Japón, o Alemania, o China, o incluso la Unión Soviética, quien ocuparia la nueva vanguardia industrial, pero lo que en efecto ha ocurrido es que la frustración de estos vaticinios se ha visto acompañada por una extraordinaria reafirmación del moderno poderío económíco y tecnológico de los Estados Unidos que, tal como ocurrió con las Indias tridentinas, ratifica de esta manera el parentesco entre la cultura industrial progenitora y su vástago americano.

Estas son las continuidades decidoras que ayudan a dilucidar y comprender algunos de los principales contrastes culturales entre el norte y el sur de América que, vale la pena agregar, no se alejan demasiado de los que hasta hoy día persisten entre España, Portugal y Gran Bretaña, 
destacando el hecho evidente que sus raices profundas no se encuentran en las interesantes y venerables costumbres y creencias de quechuas, apaches, picunches o chichimecas, sino en las instituciones y prácticas que vertebran las tradiciones culturales de los pueblos de la peninsula ibérica y de las islas británicas. Estas tradiciones tuvieron. un papel protagónico en la gestación, la plena realización y la determinación cultural de las dos grandes revoluciones de la historia modema, y se mantienen hoy dia como aportes principales en las culturas contrastantes del norte y sur de nuestro mundo, especialmente los que llevan a la interrogante de por qué las riquísimas Indias de los siglos dieciséis y diecisiete son ahora las harto menos prósperas repúblicas latinoamericanas, mientras que los entonces esmirriados caserios de los colonos ingleses en el hemisferio norte han dado origen a la nación más rica y poderosa en la historia de la humanidad. ${ }^{2}$

Es imposible siquiera intentar dar respuesta a esta grave pregunta șin primero referirse a los antecedentes históricos y reiterar el hecho definidor, que tanto las Indias del sur como las colonias del norte son sociedades transplantadas que por mucho que se hayan independizado y asumido el manto republicano, continúan emparentadas estrechamente con el lenguaje, las leyes, la disposición política y económica, la religiọn y las costumbres de las sociedades europeas progenitoras. Lo que los seres humanos hacen, importa. Lo que piensan, lo que imaginan, lo que planean hacer, lo que estiman necesario hacer, es sin duda alguna también digno de consideración, pero lo que ya se hizo tiene una importancia cualitativa que no es posible subordinar ni a esperanzas ni a,ideologias, por impecables que sean. Toda sociedad genera una cantidad inmensa de productos, residuos, vestigios y consecuencias de la acción humana, exitosa o no, completa o incompleta, siniestra o virtuosa, que desde luego incluye artefactos culturales, y que considerados conjuntamente puede sugerir una disposición animica, una manera de proceder, un modo de definir y resolver problemas, en resumen, un estilo, que además de identificable, las más de las veces refleja con bastante fidelidad el tenor dominante del momento histórico. Tanto la Contrarreforma -que bien podemos llamar la "revolución cultural española". - como la Revolución

\footnotetext{
${ }^{2}$ Esta pregunta ha generado gran número de respuestas de las cuales pocas han sido tan influyentes como la que hace ya casi un siglo ofreciera Josć Antonio Rodó en su muy leido ensayo, Ariel. Cualesquiera los méritos de la tesis presentada en esta obra, no hay duda que satisfizo a muchos y pasó a ser parte importante del bagaje cultural latinoamericano, y no son pocos los que han dormido tranquilos en el convencimiento dé que el severo dilema propuesto por el "Maestro de la juventud", se resuelve alineándonos nosotros con la noble y desinteresada espiritualidad de Ariel, y dejando para nuestros incustriosos amigos norteamericanos el materialismo vulgar y grosero de Calibán.
} 


\section{Véliz / Sur y norte de la cultura ...}

Industrial de los ingleses, generaron estilos culturales contrastantes que, habiendo ejercido una influencia formativa sobre las sociedades transplantadas, han tendido luego a perpetuarse en las instituciones y prácticas del mundo iberoamericano y en las de la modemidad industrial del momento cultural de la América de habla inglesa.

El estilo rector de la gran revolución cultural española refleja rigurosamente la convicción de que aun cuando hay una sola verdad, los errores abundan; que es razonable y justo subordinar los talentos humanos al servicio de esta verdad singular; que la conciencia del rey -o del Estado central - es la garantia más valedera del buen gobiemo y, quizás lo más importante; que la estabilidad, la permanencia y la continuidad son virtudes absolutas de la comunidad tradicional que contrastan con el carácter sospechoso y riesgoso del cambio, el desorden, la novedad y la incertidumbre.

Contrasta poderosamente con esto el estilo de la Revolución Industrial de los ingleses al asociar tanto su origen como su desarrollo y prosperidad a un proceso virtualmente irresistible y persistente de cambios tecnológicos y económicos necesariamente asociados con la novedad y el riesgo. Más aún, estos cambios, aparentemente caóticos, exigen para su realización, ordenación y buen gobierno, antes que la intervención inspirada del monarca o del Estado centralizador, el ejercicio irrenunciable de la responsabilidad individual. El buen éxito de esta secuencia ininterrumpida de transformaciones depende en gran parte de la movilidad permanente de los factores de producción, ciertamente incluyendo el factor trabajo, movilidad que casi por definición asegura la disolución irreversible de la comunidad tradicional. Como lo hicieron notar los sociólogos clásicos, la modernidad industrial nos obliga a vivir rodeados por desconocidos.

Este contraste de estilos culturales se ve asimismo reflejado en la mayúscula distancia que separa el espíritu y modalidad de la intervención de las coronas castellana e inglesa en el establecimiento, apoyo y administración de sus respectivas colonias ultramarinas. En el caso de las Indias de Castilla, especialmente bajo los grandes Austrias, es sencillamente imposible explicar la secuela histórica que va desde el descubrimiento y la conquista hasta la reglamentación prolija de cada aspecto de la vida en las nuevas españas allende el océano sin asignar un papel protagónico a la monarquía centralizadora.

En el caso de Westminster, aparte de lo que hay de verdad en aquel cliché que afirma que Gran Bretaña adquirió su imperio ultramarino en un fit of absent-mindedness, lo menos que se puede observar es que las 
colonias que más claramente otorgaron al procêso cultural del norte su carácter especialísimo, y que asumieron más tarde el liderazgo del movimiento emancipador, fueron precisamente aquéllas en que la ingerencia metropolitana fue minúscula tanto en sus orígenes como en su eventual institucionalización: Más aún, las iniciativas de Westminster, buenas o malas, tuvieron tän poca importancia en la creación como en la disolución final del imperio inglés en América. Debería ser innecesario aquí hacer hincapié acerca del hecho, por ejemplo, que el Commonwealth de Massachusetts no debe su origen ni a planes, ni a subvenciones, ni al apoyo moral; político o militar de la corona inglesa. Más aún, es posible imaginar -dádo el contexto político contemporáneo-que tanto la iniciativa de establecer aquellas colonias como su supervivencia una docena de años más tarde hayan sido completamente ignoradas por Westminster. Las frugales aldeas de la Nueva Inglaterra estaban habitadas por cristianos devotos que habían decidido emigrar por cuenta propia y que no tuvieron ni la necesidad ni la inclinación de informar a la corona acerca de sus intenciones.

La diferencia entre esta experiencia y la de las Indias castellanas y lusitanas es dramática, puesto que además del papel decisivo jugado por la corona en la.gesta del descubrimiento y conquista, hay que agregar que no hubo región alguna de las Indias, ciertamente incluyendo las capitanias brasileñas, que no haýa sido, desde su más temprano origen, objeto de prolija atención administrativa y política por parte del Estado central, incluyendo el control riguroso de las personas a quienes se autorizaba a cruzar el Atlántico. El decidor contraste en el establecinuiento y desarrollo de estas sociedades transplantadas áparece vigorosamente reiterado en la disolución de los dos imperios coloniales. En América del norte la iniciativa independentista fue absolutamente local, mientras que en iberoamérica tuvo sus origenes no en los virreinatos indianos; sino que en el derrumbe de la monarquía española que, habiendo dejado acéfalas a las colonias americanas, obligó a los vecinos a formar juntas para defender el trono del bienamado Fernando VII contra la usurpación bonapartista.

Contrastes como estos se multiplican en todos los ámbitos principales de la acción humana. Considérese, por ejemplo, aquél entre el buen uso y ordenamiento del idioma castellano que en la tradición ibérica ha quedado en manos de la venerable y centralísima Real Academia, con el dinámico y bienhumorado desorden en los usos y abusos a que es sometida diariamente la lengua de Wordsworth y Whitman; o nótese la polaridad exquisita entre la jurisprudencia codificada y centralizada de 
la tradición romana y napoleónica que preside sobre los sistemas legales de iberoamérica, con la common law de nuestros vecinos de habla inglesa, que deriva su autoridad de una infinidad de fallos que se incorporan regularmente a los cuerpos legales, pasando de este modo a constituir una jurisprudencia esencialmente basada en precedente. Basta un examen somero de los regímenes políticos de nuestro continente para constatar además el severo contraste existente entre el sólido federalismo de nuestros dos vecinos de habla inglesa, con los numerosos intentos fallidos por establecer sistemas federales en Iberoamérica, que irremediablemente sucumben bajo el peso abrumador de una tradición centralista inmensamente compatible con el estilo cultural heredado de la revolución cultural española. Por supuesto, ninguna comparación entre el norte y el sur de la cultura del nuevo mundo, podría pasar por alto la diferencia elocuente entre una religiosidad que por cinco siglos fluyó por un solo cauce católico, con la disposición cultural de los americanos del norte, que seguramente han generado más religiones, sectas y creencias exitosamente exportadas a todas las latitudes, que ningún otro pueblo de la modernidad.

Retornando entonces a la pregunta acerca del durisimo contraste entre la proeza económica del norte y las dificultades del sur, es posible sugerir que aun cuando la enumeración anterior es algo injusta, especialmente dada la complejidad del problema, basta abundantemente para demostrar que las características señeras de la Contrarreforma española, de cuyo origen y formación no es posible excluir la participación de las Indias, son parte de una vasta y rica tradición cultural que contrasta visible y definitivamente con aquélla que generó la Revolución Industrial. Mientras la modernidad industrial asigna al cambio dinámico y creador el lugar de honor entre los factores responsables por el desarrollo económico, la revolución cultural española lo rechaza decididamente. Así como la disposición predominante en el ámbito norte cohabita cómoda y tranquilamente con la movilidad de los factores de producción directamente responsable de la disolución acelerada de la sociedad tradicional, la disposición cultural predominante en el ámbito sur está hermanada con una apreciación inteligente y generosa de los valores, lealtades y afectos que son invariablemente las primeras víctimas de las transformaciones que impone la modernidad industrial.

La Revolución Industrial y la Contrarreforma son las construcciones culturales más importantes de nuestros imperios progenitores; ambas representan logros transcendentes que, de diferente manera, continúan influenciando las sociedades transplantadas del nuevo mundo. En el caso 
de la:Revolución Industrial de los ingleses, lo menos que se puede anotar es la relación funcional que existe entre un historial de realizaciones económicas y tecnológicas sin precedente, y un estilo cultural vigoroso que, además de ocupar abrumadoramente el horizonte:cultural de la América del norte, ejerce una influencia creciente sobre el resto del mundo moderno.

En cuanto a la Contrarreforma del siglo dieciséis, debe apreciarse que en su momenito y durante los dos o tres siglos que siguieron, constituyó, y con mucho; la más imponente y exitosa creación cultural del mundo ibérico, integrando magnífica y eficazmente procederes políticos y mörales sobre macizos cimientos teológicos y filosóficos. Aquella elevada estructura de victorias aunó las virtudes morales con el refinamiento estético; el coraje cívico con la imaginación creadora, la proeza piadosa con la gesta militar, la intencionalidad espiritual con el buen gobierno, proyectando, por consiguiente, una muy larga y acogedora sombra que, no obstante la melancólica secuela de fracasos que jalonan la historia de España y Portugal durante los ‘últimos siglos, ha mantenido viva en las otrora Indias imperiales la esperanza de un resurgimiento bajo la's viejas banderas. Cada sugerencia, brutal o tenue, de la posibilidad del'retomo del Estado centralizador y omnipotente - ¿la conciencia del rey?-como entidad ordenadora, en cualquiera de sus diversas formas populistas, nazistas, comunistas, radicales, falangistas, socialistas, social cristianas o comunitarias en general, revive la fe y contribuye a postergar las transformaciones necesarias para llevar adelante el proyecto modernizadior.

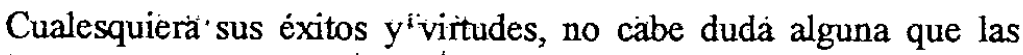
sociedades cambian; $y$ es perfectamente posible, como se ha observado repetidamente en el pasado, que cada una lleve consigo el germen de su eventual transformación." Es igualmente claro que si la clave de la modemidad industrial residièse en là adopción prolija dèl estilo cultural de la Revolución Industrial de los ingleses, el problema de Iberoamérica ya habria dejadó de sérlo. Bastäría para demostrar la validez de esta solución; por ejemplö; qué la situación excepcional de un país cómo Puerto Rico respecto de los Estados Unidos hubiera resultado en un rápido y satisfactorio proceso de modemización. Pero no es esto lơ que ha ocurrido. Por el contrario, Puerto Rico sigue exportando seres humanos que unavez en los Estados Unidos, continúan ocupando los escalones más bajos de la sociedad urbana. Esta experiencia se asemeja en forma inquietante con la de inmigrantes mejicanos que por muchos años han vivido en Canadá y los Estados Unidos sin que esto se haya traducido 
necesariamente en un mejoramiento sustancial de su condición económica semejante al que con justeza se asocia con la experiencia de los inmigrantes del sureste asiático.

Sería temerario siquiera intentar predecir el futuro de tradiciones culturales invariablemente complejas y dinámicas, sin embargo, y a modo de conclusión muy tentativa, no está enteramente fuera de lugar observar que las repúblicas americanas de la tradición ibérica que con más éxito parecen hoy día encaminadas hacia las prosperidades asociadas con la modemidad industrial, incluyen tanto aquéllas que entonces estuvieron distantes del magnífico momento virreynal, como también las que en tiempo reciente con más severidad han sufrido los desastres y desencantos de inflaciones desbocadas y otros descalabros políticos y económicos perpetrados por regímenes cegados por ineptitudes doctrinarias. 